\title{
Economic Capital Allocation for Corporate Borrowers Credit Risk Coverage*
}

\author{
Irina V. Berezinets ${ }^{1}$ and Anastasiya S. Loginova ${ }^{2}$ \\ 1 St. Petersburg State University, \\ 7/9 Universitetskaya nab., St.Petersburg, 199034, Russia \\ E-mail: berezinets@gsom.pu.ru \\ 2 Limited Liability Company "Interleasing", \\ 36a Petrogradskaya nab., St.Petersburg, 197101, Russia \\ E-mail: logns1995@gmail.com
}

\begin{abstract}
Both the estimation of economic capital for bank's credit risk coverage, and the allocation of economic capital by sources in order to determine the contribution of individual elements to total credit risk play an important role in the area of risk management of a bank. The estimation of a bank's economic capital for credit risk coverage serves as a starting point in the management of a bank's credit risk, while the allocation of economic capital to cover credit risk among individual elements allows to answer the question of how individual elements contribute to the total credit risk of a bank, which makes it possible to take certain decisions on credit risk management based on the obtained results of allocation. Nowadays, there are various theoretical methods and approaches to solve this nontrivial issue. The authors of the article attempted to implement them in practice, to estimate economic capital for credit risk coverage of a commercial bank and to allocate it among elements. This problem was solved applying the Euler allocation method and kernel regression.
\end{abstract}

Keywords: economic capital, allocation, credit risk, corporate borrowers.

\section{Introduction}

In daily activities, banks are constantly faced with numerous risks. Traditional banking risks are market, credit, operational, liquidity and others. According to the annual research conducted by the Center for the Study of Financial Innovation with the support of PricewaterhouseCoopers, credit risk has been leading the list of the most significant risks for several years ${ }^{1}$.

Credit risk could be defined as the risk of loss due to the borrowers' inability to repay the debt in full or in part.

In recent years, the approach of quantitative measurement of risk in terms of economic capital has become actively applied. The emergence of the term "economic capital" is usually attributed to the publication of Basel II Capital Accord.

The amount of economic capital required to cover risks is compared with the existing financial resources of the bank, on the basis of the ratio obtained, further decisions on risk management are made.

${ }^{*}$ This work was supported by Saint Petersburg State University under grants No 60419633

${ }^{1}$ Lascells, D. and K. Patel (2015). Banking Banana Skins 2015: The CSFI survey of bank risk - available at:https://www.pwc.com/gx/en/financial-services/pdf/Bankingbanana-skins-2015-final.pdf

https://doi.org/10.21638/11701/spbu31.2021.02 
Banks estimate economic capital to cover the major banking risks such as market, credit, operational, and others using internal models.

The main goal of the study presented in the article was to estimate economic capital for credit risk coverage of the segment of corporate borrowers.

In order to achieve the goal stated, firstly, it was necessary to estimate total economic capital for credit risk coverage. In the study Monte-Carlo simulation was applied in order to estimate economic capital. The main attention was paid to estimation of economic capital of one of the most significant risks that is credit risk.

On the next stage economic capital was allocated and contribution of corporate borrowers' segment to total economic capital was found. The main difficulty arising on practice is allocation of economic capital and calculation of risk contributions of its individual elements. To solve this rather nontrivial task, the authors applied Euler allocation method. In the study presented, there was made an attempt to allocate economic capital and find corporate borrowers risk contribution.

The results of the study and presented in empirical part of the work algorithm could be applied on practice in sphere of risk-management.

\section{Economic Capital for Credit Risk Coverage}

The topic of economic capital is widely discussed since the early 2000s. This topic received such wide discussion among practitioners and theorists after the release of Basel II Capital Accord. Economic capital has become one of the important components of internal risk management system of banks and other financial organizations.

According to the definition presented in Basel II, economic capital is a set of methods or practices that allow banks to consistently assess risk and generate capital to cover the economic consequences associated with conducting risky activities ${ }^{2}$. Another common definition of economic capital is an estimate of the worst possible decline in the institution's amount of capital at a specified confidence level, within a chosen time horizon ${ }^{3}$. The confidence level represents the probability at which institution remains solvent over the specified time horizon.

It is important to differentiate economic capital from regulatory capital. Regulatory capital is the main tool for regulating the activities of the bank by supervisors. It represents the minimum amount of sufficiency of the bank's own funds and is expressed in the form of standard H1. Economic capital is rather management requirement than requirement of supervisor. It is the amount that is necessary to be solvent with a high probability taking into account risk profile.

One of the reasons for the widespread and active use in practice of the economic capital concept is its integration into the decision-making process. Economic capital contributes to the formation of a more accurate pricing of banking products; used to assess capital adequacy; allows the use of indicators of the effectiveness taking account of risk, such as risk-adjusted return on capital (RAROC) and maintain bet-

\footnotetext{
${ }^{2}$ Range of practices and issues in economic capital frameworks / Basel Committee on Banking Supervision. - 2009. - available at: https://www.bis.org/publ/bcbs152.pdf (accessed October 25,2019)

${ }^{3}$ Manuylenko, V. V. (2011). The concept of economic capital of a commercial Bank . Finance and credit , 13(445), 8-17.
} 
ter risk management of the bank ${ }^{4}$. According to (Wang, 2016) institutions estimate economic capital for several purposes, such as, capital budgeting, credit product pricing, performance measurement, rating agencies and regulatory discussions and others.

Banks analyse economic capital on different levels. Economic capital can be considered both in aggregated form for the entire bank as a whole, and in the context of certain types of risk. Economic capital is estimated for coverage of all significant banking risks, such as credit, market and operational.

Discussion of the concept of economic capital would not be complete without definition of terms expected and unexpected losses. In the process of doing business, banking institutions suffer certain losses in one way or another. Based on experience, banks can estimate their expected value. This value is called expected losses. From the statistical point of view, the amount of expected losses is the mathematical expectation of the actual losses incurred by the bank. Depending on the amount of expected losses, the bank forms provisions. Moreover, the bank covers expected losses by charging a risk premium from borrowers depending on their creditworthiness ${ }^{5}$. Often the amount of expected losses is considered as cost of doing business ${ }^{6}$. Thus, expected losses do not pose a serious risk to the bank.

However, there is another part of the losses, called unexpected losses, which exceeds the expected losses and has a low probability of realization. In comparison with expected losses, unexpected losses pose a serious threat to the bank and could potentially have a devastating effect on the bank's solvency. One of the most widely discussed examples of the negative consequences of realization of unexpected losses is the sub-prime crisis of 2007-2008.

The process of economic capital to cover credit risk estimation can be divided into two main stages. The first step is to assess the credit risk of an individual lender. The second stage is modelling the credit risk of the portfolio, which involves modelling the structure of dependence between borrowers.

\section{Estimation of Economic Capital}

One of the key elements in calculating the bank's economic capital is estimation of value-at-risk (VaR), which is the most common metric for quantifying risk. VaR is an intuitive and easily interpretable indicator, as it is measured in monetary units and can be used to assess any type of risk.

In the general case, value-at-risk can be defined as the maximum possible loss that can occur in a given period of time, expressed in monetary terms, with a certain confidence probability ${ }^{7}$.

\footnotetext{
${ }^{4}$ Burns, R. L. (2004). Economic Capital and the Assessment of Capital Adequacy.available at:https://www.fdic.gov/regulations/examinations/supervisory/insights/siwin04/ siwinter04-article1.pdf (accessed October 25,2019)

${ }^{5}$ Fantazzini, D. (2008). Econometric analysis of financial data in risk management. In: SApplied econometrics Vol. 2(10), pp. 91-137. (in Russian).

${ }^{6}$ Klaasen, P. and I. Eeghen (2009). Economic capital: how it works and what every manager needs to know. Elsevier.

${ }^{7}$ Valaskova, K., A. Siekelova, and I. Weissova (2017). Credit Risk Measurement Using VaR Methodology. In: Advances in Applied Economic Research. (Tsounis, N., Vlachvei, A., eds.) Springer, Cham.
} 
At present, three methods for calculating VaR can be distinguished, namely, the parametric, historical, and Monte Carlo methods. According to the parametric method, also known as the method of dispersion-covariance (variance-covariance) or analytical method, $V a R$ is calculated as a function of certain parameters, mainly on the expectation and variance. When using the historical method, historical data are used to construct the distribution of a random variable by which a quantile is found equal to a given confidence probability. The Monte Carlo method is to simulate a large number of scenarios of the distribution of losses in the loan portfolio and finding the specified quantile.

When calculating $V a R$ for assessing credit risk and subsequent calculation of economic capital, the portfolio approach is used, which involves assessing the credit risk of an individual borrower and then aggregating individual assessments in order to obtain an assessment of the credit risk of the entire portfolio, taking into account the effect diversification ${ }^{8}$.

\subsection{Aggregation Methods}

Banks differ in their approaches to aggregating individual risk assessments for calculating economic capital, and some methods are more complex than others. In the work (Shaw et al., 2011) describes the most common methods:

1. Simple summation method;

2. Method of a fixed percentage (fixed diversification percentage);

3. Method, based on the application of the correlation matrices (variance-covariance method);

4. Method based on the use of copulas.

Each of the above methods has its advantages and disadvantages. The choice of a particular method depends on a compromise between various factors, such as model accuracy and quality (model accuracy, model consistency, and numerical accuracy), availability of necessary data, intuitiveness, flexibility. In practice, banks can apply several methods at the same time, which will complement each other and contribute to improving the quality of the final assessment.

In Table 1 the main methods and the advantages and disadvantages of each method are presented.

The first two methods are the simplest and most intuitive. The simple summation method involves adding up individual estimates of economic capital. This method ignores the potential benefits of diversification. This method uses the assumption that the correlation between individual risks is 1 .

The fixed interest method consists in reducing the fixed capital estimate obtained using the simple summation method. The main disadvantage of these methods is the fact that they do not always correctly reflect the real assessment of the risk that the bank faces in practice. One method that can cope with the shortcomings of traditional methods is an approach based on the copulas.

In the study (Fenech et al., 2015), the authors also use copula-functions to model the structure of the relationship between defaults of borrowers for the $\mathrm{S}$ and $\mathrm{P}$

\footnotetext{
${ }^{8}$ Choudhry, M. 2013. An Introduction to Value-at-Risk, 5th ed. John Wiley and Sons Ltd, The Atrium, Southern Gate, Chichester, West Sussex.Choudhry, M. (2013). An Introduction to Value-at-Risk. 5th ed. John Wiley and Sons Ltd, The Atrium, Southern Gate, Chichester, West Sussex.
} 
Table 1. Advantages and disadvantages of aggregation methods of economic capital

\begin{tabular}{|c|c|}
\hline Method & Disadvantages \\
\hline $\begin{array}{l}\text { Simple summa- } \\
\text { tion }\end{array}$ & $\begin{array}{l}\text { Simple, conser- Do not take into account non-linearity, do not take } \\
\text { vative } \\
\text { into account diversification effect }\end{array}$ \\
\hline $\begin{array}{l}\text { Fixed percentage } \\
\text { method }\end{array}$ & $\begin{array}{l}\text { Simple, take into } \\
\text { account diversifi- Do not take into account non-linearity } \\
\text { cation effect }\end{array}$ \\
\hline $\begin{array}{l}\text { Correlation ma- } \\
\text { trices }\end{array}$ & $\begin{array}{l}\text { Simple, under- } \\
\text { standable, take } \\
\text { into account Do not take into account non-linearity, difficult in es- } \\
\text { diversification timation of coefficients of correlation } \\
\text { effect }\end{array}$ \\
\hline Copulas & $\begin{array}{l}\text { Flexible, take } \\
\text { into account Difficult, require high computing power } \\
\text { non-linearity }\end{array}$ \\
\hline
\end{tabular}

Source: [Scandizzo, S. (2016). The Validation of Risk Models: A Handbook for Practitioners. 1st ed. Palgrave Macmillan, UK.]

Consumer Credit Index, which aggregates information on the frequency of defaults of borrowers from four main groups, namely, car loans, banking cards and two types of mortgage lending. In addition, the authors discuss the question of why the copula Gaussian function caused so much instability in the 2007-2008 years and has proved so ineffective in predicting credit risk. The authors conduct research in the periods before the crisis of 2008 and after, trying to answer the question posed. As a result of an empirical study, the authors came to the conclusion that the family of Archimedean copula - functions, in particular, the Gumbel copula - function, allows one to more correctly model the relationship between borrowers, especially in the distribution tails.

The authors of the study (Fisher and Jakob, 2013) used copula functions to model the relationship between the sectors of the economy that represent the loan portfolio. Modelling dependencies between sectors is more convenient in the sense that it allows us to simplify the structure of dependencies and move on to a model of lower dimension. The study was conducted on a hypothetical loan portfolio, which includes borrowers from various sectors of the economy, such as telecommunications, energy, finance, consumer goods and others. The focus of the work was to show the effect of modelling dependencies between sectors using copula-functions of different families on various credit risk assessments, such as VaR, Expected Shortfall, standard deviation and others. The study used various types of copula-functions, such as the copula-function of Gaussian, Student, Gumbel, Generalized hyperbolic and others. As a result of the study, the authors came to the conclusion that the result of modelling using the Gaussian copula function is an underestimation of the credit risk assessed using various metrics. In the case of economic capital, underestimation was $10 \%$ to cover credit risk.

Another approach to assessing credit risk using factor copula functions is presented in (Lu et al., 2017). The assumption is made that the correlation between borrowers and, accordingly, their defaults is due to their exposure to the so-called systematic risk. In order to take this fact into account, a number of authors used a factor model, for example, (Andersen and Sidenius, 2004; Lee and Poon, 2014; Lee 
and Yang, 2019). This method allows to take into account the correlation between borrowers indirectly through their correlation with a common factor. However, as the authors point out, this method has the following drawback, namely, the assumption of a constant and linear dependence structure.

As a result, the authors came to the following conclusions. The authors concluded that a systematic factor affects both the probability of default and recovery rates. The authors also found that the correlation between borrowers and the state of the economy is higher during periods when the economy is in a state of tension. It is worth noting that the authors themselves note that one of the further areas of research is the use of other types of copula- functions, which allow more correctly reflect the dependence in the tails of the distribution.

\section{Economic Capital Allocation}

After determining the amount of economic capital, it should be distributed among the various components of the portfolio. In the literature, the contribution of an individual element to the total economic capital is usually called the risk contribution and the process of distributing the total economic capital to the individual elements called capital allocation ${ }^{9}$. Economic capital could be allocated among lines of business, product types within line of business, types of risks, territories, departments and other ${ }^{10}$. This depends on the purpose of allocation.

Economic capital is allocated for different purposes. It is necessary in decisionmaking process, contributes to make more thorough decisions, support business planning. Moreover, economic capital allocation could be beneficial in setting prices for banking products, estimation of profitability, setting limits and applying riskbased compensation systems. Furthermore, economic capital allocation plays very important role in credit portfolio management ${ }^{11}$.

To allocate economic capital over the elements, it is necessary to distribute the expected losses of EL and VaR. It is worth noting that it is the allocation of VaR in practice that causes the greatest difficulty. In this regard, the bulk of the work is focused specifically on the allocation of VaR.

There is no unique method for allocating economic capital. Each approach has benefits and drawbacks and may be suitable for a given management application.

In (Mausser and Rosen 2007) the following broad classification of approaches is presented.

Unconsolidated Approach With this approach, VaR is calculated separately for each element without taking into account the fact that there is a relationship between the individual elements. This method does not allow to take into account the positive effect of diversification and most often the assessment of the EC element obtained with this approach to VaR allocation is overestimated. In this regard, the amount of EC elements will exceed the value of the total EC calculated for the loan portfolio for all elements.

\footnotetext{
${ }^{9}$ Tasche, D. (2008). Capital Allocation to Business Units and Sub-Portfolios: the Euler Principle. In: Pillar II in the New Basel Accord: The Challenge of Economic Capital. Risk Books.

${ }^{10}$ Wang, M. (2016). Economic Capital Allocation. Mathematics and Statistics Faculty of Science and Engineering Abo Akademi University.

${ }^{11}$ Ibid.
} 
Incremental approach The essence of this approach is to find the difference between the portfolio EC, VaR for which was estimated by the distribution of losses for the portfolio, which includes all elements, and the portfolio EC, VaR for which was estimated by the distribution of portfolio losses, which includes all elements, except for the element for which the contribution value is determined. Thus, the difference obtained is the desired value of the contribution of an individual element to the total EC. Also, as in the previous approach, the drawback of the incremental approach is that it does not allow distributing the EC in such a way that the total amount of the EC elements is equal to the total value of the EC loan portfolio.

Marginal approach This approach is superior to the two previous ones in the sense that this approach allows you to distribute the VaR of the portfolio in such a way that as a result, the sum of the EC elements is equal to the total EC. The main method corresponding to this approach is the Euler allocation method.

According to a wide range of works Euler allocation method assumed to be the more appropriate and accurate method for allocation. The main advantage of the method is that it allows to get subadditive decomposition of economic capital. The risk contributions of elements add up to the total economic capital. Authors (Litterman, 1996; Tasche, 1999) argued that Euler allocation is rationale from the economic sense. Authors of (Kalkbrener, 2005) argued that only Euler allocation is compatible with the diversification axiom.

In (Balog, 2011) author compare such methods as activity-based method, Beta (covariance-based) method, incremental method, cost gap method, Shapley method and Euler method. Authors were aimed to compare all these methods and find the method which satisfies the criteria of full allocation, core compatibility, symmetry, riskless allocation and flexibility and applicability on practice. It was found that Euler method outperform all other methods and show the best result.

\section{Empirical Study}

The main goal of the study is to estimate economic capital for credit risk coverage of the segment of corporate borrowers. On the first stage, it is required to estimate total economic capital for credit risk coverage $\left(E C^{\text {total }}\right)$. On the next stage, economic capital should be allocated and contribution of corporate borrowers segment to total economic capital should be calculated $\left(E C^{c o r p}\right)$.

\subsection{Estimation of Total Economic Capital}

At the first stage, the total economic capital for the credit portfolio was estimated. Economic capital to cover the risk of a loan portfolio can be defined as the difference between the VaR value and the expected losses (1)

$$
E C^{\text {total }}=V a R \alpha-E L .
$$

Economic capital for credit risk coverage is an estimate of accepted by bank credit risk based on a probabilistic estimation of potential future losses arising from the realization of credit risk.

It is worth noting that some of the loans included in portfolio accounted for on individual base and some of the loans a grouped into homogeneous sub portfolios. Loans grouped into homogeneous subportfolios assumed to be identical with respect to asset correlations $\rho$, probability of default, and loss given default. 
It is important to distinguish between individual loans and loans grouped into homogeneous subportfolios because it implies certain features in the modelling approach.

Individual Base Denote by Loss $_{i, i n d}$ the losses on the loan accounted for on individual base, which is a random variable.

$$
\operatorname{Loss}_{i, \text { ind }}=L G D_{i} * E A D_{i} * I_{A_{i} t<B_{i}}
$$

where $L G D_{i}$ - loss given default, $E A D_{i}$ - exposure at the default, $I_{A_{i} t<B_{i}}$ - binary variable that takes the value 1 if company $i$ is in default state and 0 otherwise.

The default state of the company is defined as follows. It is assumed that company $i$ at time $t$ will go into default if its asset value is less than its obligations $B_{i}$, that is: $A_{i t}<B_{i}$.

In (Vasichek, 2002) it is assumed that the change in the value of the company can be described using geometric-Brownian motion:

$$
d A_{i t}=\mu_{i} A_{i t} d t+\sigma_{i}+A_{i t} d W_{t}
$$

where $A_{i t}$ - value of the assets of the $i-t h$ company at time $t, \mu_{i}$, - mathematical expectation of the value of the assets of the $i-t h$ company, $\sigma_{i}$ - standard deviation of the value of the assets of the $i-t h$ company, $W$ - Wiener process, $\forall i=1 \ldots n$. By solving the stochastic differential equation, the value of the assets of the $i-t h$ company at time $t$ can be obtained.

$$
A_{i t}=A_{i 0} e^{\left(\mu_{i}-1 / 2 \sigma_{i}^{2}\right) t+\sigma_{i} W_{t}}
$$

By the definition of the Wiener process, there is a representation: $W t=\xi(t) \sqrt{t}$, where $\xi(t)$ is the standard normally distributed random variable $\in N(0,1)$. According to definition of the default state presented earlier company $i$ at time $t$ will default if its asset value $A_{i t}$ is less than the value of its obligations $B_{i}$, that is: $A_{i t}<B_{i}$. Consider the probability of such an event $P\left[A_{i t}<B_{i}\right]$.

$$
\begin{gathered}
A_{i t}=A_{i 0} e^{\left(\mu_{i}-1 / 2 \sigma_{i}^{2}\right) t+\sigma_{i} \xi_{i}(t) \sqrt{t}}, \\
\frac{A_{i t}}{A_{i 0}}=e^{\left(\mu_{i}-1 / 2 \sigma_{i}^{2}\right) t+\sigma_{i} \xi_{i}(t) \sqrt{t}}, \\
\ln \frac{A_{i t}}{A_{i 0}}=\left(\mu_{i}-1 / 2 \sigma_{i}^{2}\right) t+\sigma_{i} \xi_{i}(t) \sqrt{t} .
\end{gathered}
$$

Thus,

$$
\begin{gathered}
\xi_{i}(t)=\frac{1}{\sqrt{t} \sigma_{i}}\left(\ln \frac{A_{i t}}{A_{i 0}}-\left(\mu_{i}-1 / 2 \sigma_{i}^{2}\right) t\right), \\
P\left[A_{i 0} e^{\left(\mu_{i}-1 / 2 \sigma_{i}^{2}\right) t+\sigma_{i} \xi_{i}(t) \sqrt{t}}<B_{i}\right]= \\
P\left[e^{\left(\mu_{i}-1 / 2 \sigma_{i}^{2}\right) t+\sigma_{i} \xi_{i}(t) \sqrt{t}}<\frac{B_{i}}{A_{i 0}}\right] \\
P\left[\left(\mu_{i}-1 / 2 \sigma_{i}^{2}\right) t+\sigma_{i} \xi_{i}(t) \sqrt{t}<\ln \frac{B_{i}}{A_{i 0}}\right] \\
P\left[\sigma_{i} \xi_{i}(t) \sqrt{t}<\ln \frac{B_{i}}{A_{i 0}}-\left(\mu_{i}-\frac{1}{2} \sigma_{i}^{2}\right) t\right]
\end{gathered}
$$




$$
P\left[\xi_{i}(t)<\frac{1}{\sigma_{i} \sqrt{t}}\left(\ln \frac{B_{i}}{A_{i 0}}-\left(\mu_{i}-\frac{1}{2} \sigma_{i}^{2}\right) t\right] .\right.
$$

Denote the expression $\frac{1}{\sigma_{i} \sqrt{t}}\left(\ln \frac{B_{i}}{A_{i 0}}-\left(\mu_{i}-\frac{1}{2} \sigma_{i}^{2}\right) t\right]$ by $c_{i}$ that is the threshold value or the default point of the $i-t h$ company $\forall i=1 \ldots n$.

Then we get that $P\left[\xi_{i}<c_{i}\right]$. Which, by definition, is a distribution function of $F_{\xi}\left(c_{i}\right)$.

If,

$$
P\left[\xi_{i}(t)<c_{i}\right]=P D_{i}
$$

That is true the following

$$
F_{\xi}\left(c_{i}\right)=P D_{i}
$$

And

$$
\begin{gathered}
c_{i}=F_{\xi}^{-1}\left(P D_{i}\right), \\
P\left[\xi_{i}(t)<F_{\xi}^{-1}\left(P D_{i}\right)\right]=P\left[A_{i t}<B_{i}\right] .
\end{gathered}
$$

As noted above, the quantity $\xi_{i}(t)$ in (6) in the literature is called the "creditworthiness of the borrower", is a standard normal value and can be represented as the sum of two other random variables, one of which $V$ is the same for all companies, and the second $-\varepsilon$ is specific to each company.

$$
\xi_{i}(t)=\sqrt{\rho} V+\sqrt{1-\rho} \varepsilon_{i t} .
$$

In expression (7), $V$ - systematic risk factor; $\varepsilon_{i, t}$ - specific (idiosyncratic) factor of the $i-t h$ borrower; $\rho$-correlation coefficient between the assets of the $i-t h$ and $j-t h$ companies. It should be noted that the random variables $V, \varepsilon_{1, t}, \varepsilon_{2, t} \ldots$ $\varepsilon_{n, t}$ - are assumed to be independent in the aggregate. In addition, $V \in N(0,1)$; $\varepsilon_{i, t} \in N(0,1) \forall i=1 \ldots n$.

Return to the expression (2) in which the binary variable $I_{A_{i} t<B_{i}}$ was introduced. This variable takes the value 1 in the case of default and 0 otherwise. According to definition of default state the company will default if $A_{i t}<B_{i}$. That is equivalent to $\xi_{i}(t)<c_{i}$.

Thus, in order to calculate Loss $_{i, \text { ind }}$, the following steps should be performed:

1. Calculate $\xi_{i}(t)$ applying expression (7);

2. Calculate $c_{i}$ applying formula (5);

3. Compare the value $\xi_{i}(t)$ and $c_{i}$ and calculate $I_{A_{i} t<B_{i}}$ :

$\xi_{i}(t)<c_{i}$, then $I_{A_{i} t<B_{i}}=1$;

$\xi_{i}(t)>=c_{i}$, then $I_{A_{i} t<B_{i}}=0$.

4. Calculate Loss $_{i, \text { ind }}$ using expression (2).

After repeating these steps $m$ times for each individual borrower the loss distribution for individual borrower could be obtained $\left(\operatorname{Loss}_{i, \text { ind }}^{1} \ldots \operatorname{Loss}_{i, \text { ind }}^{m}\right)$.

Homogenous Subportfolio Base

For calculation of $L_{o s s}$ sub of homogeneous subportfolios the following modifications should be included. Let us return to expression (4) and rewrite it taking into account (7). 


$$
\begin{gathered}
P\left[\xi_{i}(t)<c_{i}\right]=P\left[\left(\sqrt{\rho} V+\sqrt{1-\rho} \varepsilon_{i t}\right)<c_{i}\right]= \\
P\left[\left(\sqrt{\rho} V+\sqrt{1-\rho} \varepsilon_{i t}\right)<F_{\xi}^{-1}\left(P D_{i}\right)\right]= \\
P\left[\varepsilon_{i}<\frac{F_{\xi}^{-1}\left(P D_{i}\right)-\sqrt{\rho} V}{\sqrt{1-\rho}}\right]=F_{\varepsilon}\left(\frac{F_{\xi}^{-1}\left(P D_{i}\right)-\sqrt{\rho} V}{\sqrt{1-\rho}}\right)=\hat{p} .
\end{gathered}
$$

Note that in expression (4), $P D_{i}$ indicates the unconditional probability of default, while the proposed approach for modelling the borrower's creditworthiness has led to the fact that now the probability $P\left[\varepsilon_{i}<\frac{F_{\xi}^{-1}\left(P D_{i}\right)-\sqrt{\rho} V}{\sqrt{1-\rho}}\right]$ from (8) becomes a function of the systematic factor $V$, and, generally speaking, becomes a random variable. It is worth noting that, according to the assumption of portfolio homogeneity in the Vasicek model, the probability ${ }^{p}$ is the same for all borrowers in subportfolio. Thus, the formula for losses for loans accounted on homogenous subportfolio base presented as:

$$
L o s s_{j, s u b}=L G D_{j, s u b} * E A D_{j, s u b} * \hat{p} .
$$

Thus, in order to calculateLoss $s_{j, s u b}$ the following steps should be performed:

1. Calculate ${ }^{p}$ applying (8);

2. Calculate $\operatorname{Loss}_{j, s u b}$ according to expression (9).

After repeating these steps $m$ times for each homogenous subportfolio the loss distribution for subportfolio is generated ( $\operatorname{Loss}_{j, s u b}^{1}$ в $\left.{ }_{\mid}^{\mid} \operatorname{Loss}_{j, s u b}^{m}\right)$.

After estimation of losses of individual borrowers and homogenous subportfolio losses. The total portfolio losses should be estimated. In order to aggregate losses and estimate total portfolio losses copulas were applied. As a result, the distribution of total portfolio losses could be found ( $\operatorname{Loss}_{\text {total }}^{1}$ в $\left.\varpi_{\mid}^{l} \operatorname{Loss}_{\text {total }}^{m}\right)$.

Based on the obtained sample of portfolio loss values, the expected losses $(E L)$ applying formula (10) and $V a R \alpha$ with a given confidence probability could be estimated.

$$
E L=E\left[\text { Loss }^{\text {total }}\right]=\frac{1}{m} \sum_{1}^{m} \operatorname{Loss}_{m}^{\text {total }}
$$

where $m$ - number of simulations. Finally, total economic capital is estimated as:

$$
E C^{\text {total }}=V a R \alpha-E L .
$$

At this step, the stage of estimation of total economic capital $\left(E C^{\text {total }}\right)$ is completed. The next task is to allocate it and estimate the economic capital of corporate borrowers segment $\left(E C^{\text {corp }}\right)$.

\subsection{Economic Capital Allocation}

According to expression (11), EC total consists of two elements. To allocate $E C^{\text {total }}$ over the elements, it is necessary to distribute the expected losses and $V a R \alpha$. It is worth noting that it is the allocation of $V a R \alpha$ in practice that causes the greatest difficulty. In this regard, the bulk of the work is focused specifically on the allocation of $V a R \alpha$ on elements of the loan portfolio.

The key problem in $V a R \alpha$ allocation is that, in contrast to the expected losses, $V a R \alpha$ is not subbaditive, and therefore determining which part of the total $V a R \alpha$ 
is occupied by an element is a rather non-trivial task that requires the use of certain approaches and special tools. In this study the Euler allocation was used. The reason is that according to a range of studies (Litterman, 1996; Tasche 1999; Kalkbrener, 2005; Balog, 2011) this method assumed to be the most accurate one.

For computational purposes the portfolio was separated into two elements only, namely, element of corporate borrowers and all other borrowers.

Denote by $C_{\text {corp }}^{V a R}$ and $C_{\text {other }}^{V a R}$ the contributions of segments of corporate borrowers and other borrowers to total portfolio $V a R \alpha$, obtained using the Euler allocation.

According to the Euler allocation principle, $C_{\text {corp }}^{V a R \alpha}$ and $C_{\text {other }}^{V a R \alpha}$ can be defined as:

$$
\begin{aligned}
C_{\text {corp }}^{V a R \alpha} & =x_{\text {corp }} \frac{\partial V a R \alpha}{\partial x c o r p}, \\
C_{\text {other }}^{V a R \alpha} & =x_{\text {other }} \frac{\partial V a R \alpha}{\partial x o t h e r},
\end{aligned}
$$

where $x_{\text {corp }}, x_{\text {other }}$ - shares of the elements of corporate and other borrowers in total portfolio, respectively. In (Gourieroux et al., 2000) it was proved that for an expression of the form $\frac{\partial V a R \alpha}{\partial x k}$, the following representation holds:

$$
C_{k}^{V a R \alpha}=x_{k} \frac{\partial V a R \alpha}{\partial x k}=E\left[\operatorname{Loss}^{k} \mid \text { Loss }^{\text {total }}=\text { VaR } \alpha .\right.
$$

Then, expressions (12) and (13) can be written in the following form:

$$
\begin{aligned}
& C_{\text {corp }}^{\text {VaR } \alpha}=x_{\text {corp }} \frac{\partial V a R \alpha}{\partial x \operatorname{cor} p}=E\left[\text { Loss }^{\text {corp }} \mid \text { Loss }^{\text {total }}=\text { VaR } \alpha\right], \\
& C_{\text {other }}^{V a R \alpha}=x_{\text {other }} \frac{\partial V a R \alpha}{\partial x o t h e r}=E\left[\text { Loss }^{\text {other }} \mid \text { Loss }^{\text {total }}=\text { VaR } \alpha .\right.
\end{aligned}
$$

Thus, in order to conduct Euler allocation, it is necessary to find the corresponding conditional mathematical expectations. Traditionally, the values of the conditional mathematical expectation are set by the regression function, and the specification of the model assumes the presence of unknown parameters and probabilistic assumptions about model errors.

In this paper, for estimating unknown conditional expectations $E\left[\right.$ Loss $^{\text {corp }} \mid$ Loss $\left.^{\text {total }}=V a R \alpha\right], E\left[\right.$ Loss $^{\text {other }} \mid$ Loss $\left.^{\text {total }}=V a R \alpha\right]$, nonparametric regressions, in particular kernel regressions, was applied.

If the expression for the regression model and denote the regression function by $\hat{E}\left[\right.$ Loss $^{\text {corp }} \mid$ Loss $\left.^{\text {total }}=\mathrm{VaR} \alpha\right]$, then the estimate of nonparametric kernel regression can be found by the formulas:

$$
\hat{E}\left[\text { Loss }^{\text {corp }} \mid \text { Loss }^{\text {total }}=V a R \alpha\right]=n^{-1} \sum_{i=1}^{n} W_{h i}(\text { VaR } \alpha) \text { Loss }_{\text {corp }} .
$$

The estimate, (14) can be interpreted as the weighted average of the Loss ${ }^{\text {corp }}$ variable with the weight $W_{h i}(V a R \alpha)$, which depends on the distance between $V a R \alpha, L_{o s} s^{\text {total }}$ and the parameter $h$ called bandwidth.

Expression (14) can be estimated using the Nadaraya-Watson kernel estimator. The function $K$ is used as the kernel:

$$
\hat{E}\left[\operatorname{Loss}_{1} \mid \text { Loss }^{\text {total }}=\text { VaR } \alpha\right]=n^{-1} \frac{\sum_{i=1}^{n} K_{h}(\text { VaR-Loss }}{\left.n^{\text {total }}\right) \text { Loss }_{1}} .
$$


The bandwidth $h$ was estimated by rule of thumb of Silverman presented in (Pagan and Ullah, 1999):

$$
h=1,06 \sigma M^{-\frac{1}{5}},
$$

where $\sigma$-standard deviation of the total losses, $M$ - number of Monte-Carlo simulations that is equal to 2208. As a kernel standard normal density was used.

Taking into account aforementioned, expression for economic capital estimation could be presented as follows:

$$
E C=\left(C_{\text {corp }}^{V a R \alpha}+C_{\text {other }}^{\text {VaR }}\right)-E L .
$$

By the property of mathematical expectation, the value of expected losses $(E L)$ is the sum of the mathematical expectations of individual elements:

$$
E L=E\left[\text { Loss }^{\text {total }}\right]=E\left[\text { Loss }^{\text {corp }}\right]+E\left[\text { Loss }^{\text {other }}\right] .
$$

Thus,

$$
E C=\left(C_{\text {corp }}^{\text {VaR } \alpha}+C_{\text {other }}^{\text {VaRo }}\right)-\left(E\left[\text { Loss }^{\text {corp }}\right]+E\left[\text { Loss }^{\text {other }}\right]\right) .
$$

Introduce the following notations:

$$
\begin{aligned}
E C^{\text {corp }} & =C_{\text {corp }}^{\text {VaRo }}-E\left[\text { Loss }^{\text {corp }}\right], \\
E C^{\text {other }} & =C_{\text {other }}^{V a R \alpha}-E\left[\text { Loss }^{\text {other }}\right] .
\end{aligned}
$$

And rewrite the expression (15) with the notations above:

$$
E C^{\text {total }}=\left(C_{\text {corp }}^{\text {VaR } \alpha}-E\left[\text { Loss }^{\text {corp }}\right]\right)+\left(C_{\text {other }}^{\text {VaR } \alpha}-E\left[\text { Loss }^{\text {other }}\right]\right) .
$$

\subsection{Practical Implementation}

Estimation of portfolio-wide economic capital for credit risk coverage and its allocation was carried out on the basis of credit portfolio of Russian commercial bank that is in the top 20 by assets value. The economic capital was estimated on 01.01.2018.

Considered credit portfolio is represented by corporate and retail borrowers. The number of borrowers amounted to about. All borrowers are distributed between 5 industries, such as Trade and Cyclicals, Financials, Construction and REITs, Retail and Other. Fig. 1 shows the structure of the portfolio by the amount of exposure.

As it could be seen, the category of other borrowers dominates in the structure of the credit portfolio. The share of the exposure of other borrowers to the total exposure amounted to $39 \%$. On second place in terms of the exposure is the retail borrowers. On the third place borrowers from financial industry. To a lesser extent, borrower's construction and REITs and trade and cyclicals are represented in credit portfolio.

Each borrower in portfolio is characterized by following parameters, namely, loss given default $\left(L G D_{i}\right)$, exposure at default $\left(E A D_{i}\right)$, probability of default $\left(P D_{i}\right)$ and correlation with systematic factor that represent market risk $(\rho)$. These parameters were used as inputs in Monte-Carlo simulation.

At the first step, the sample $\operatorname{Loss}_{i, \text { ind }}^{1} \ldots \operatorname{Loss}_{i, \text { ind }}^{m}$ for each individual borrower $i$ was generated applying algorithm for estimation of losses of individual borrowers. 


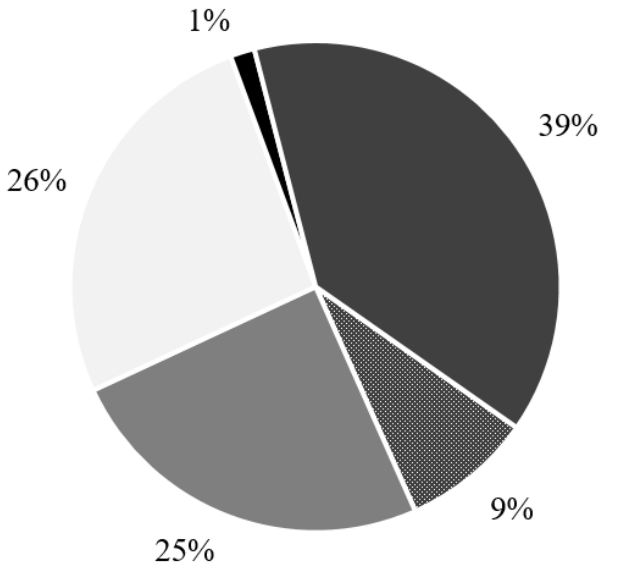

Construction\&REITs

- Financials

Other-Retail

- Trade\&Cyclicals

- Other

Fig. 1. Structure of credit portfolio by industry as of 2018

Then, the sample $\operatorname{Loss}_{j, s u b}^{1} \ldots \operatorname{Loss}_{j, s u b}^{m}$ for each homogeneous suportfolio $j$ was generated using algorithm for estimation of losses of homogenous subportfolios.

On the next step, total portfolio losses were generated applying copula. The simulation was carried out by means of MATLAB software package. In the simulation was used Gaussian copula. Figure 2 represent histogram of portfolio loss distribution generated applying Gaussian copula.

Based on the obtained loss distribution the following indicators were estimated, namely, $V a R_{0,95}$, expected losses $E L$ and portfolio-wide economic capital. The results are presented in Table 2. The economic capital amounted to 18279 million Rub. as on 2018.

Table 2. Estimated values of $V a R, E L$, and $E C$

\begin{tabular}{lll}
\hline VaR $R_{0,95}$, mln.Rub & $E L$, mln.Rub & $E C$, mln.Rub \\
\hline 30185 & 11907 & 18279 \\
\hline
\end{tabular}

The next step after estimation portfolio-wide economic capital was its allocation among the elements of the portfolio. As a simplification, the portfolio was divided into two elements, namely, the element of corporate borrowers and element of other borrowers. The share of corporate borrowers in total portfolio accounted to $24 \%$. The share of other borrowers accounted to $76 \%$. The structure is presented in Fig. 3 .

The following conditional expectations were estimated applying kernel regression with Gaussian kernel:

$$
\begin{aligned}
& E\left[\text { Loss }^{\text {corp }} \mid \text { Loss }^{\text {total }}=\operatorname{VaR}_{0,95}\right]=C_{\text {corp }}^{\text {VaR }} R_{0,95}, \\
& E\left[\text { Loss }^{\text {other }} \mid \text { Loss }^{\text {total }}=\text { VaR }_{0,95}\right]=C_{\text {other }}^{\text {VaR }} .
\end{aligned}
$$




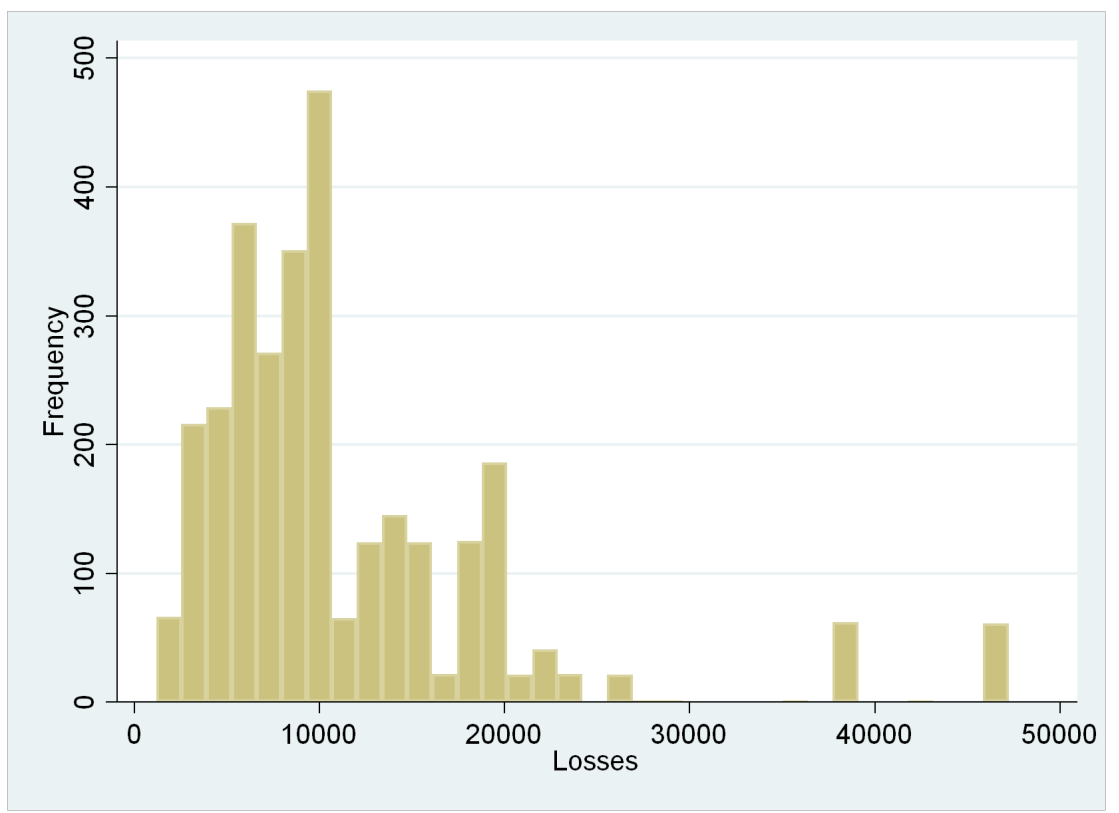

Fig. 2. Portfolio loss distribution

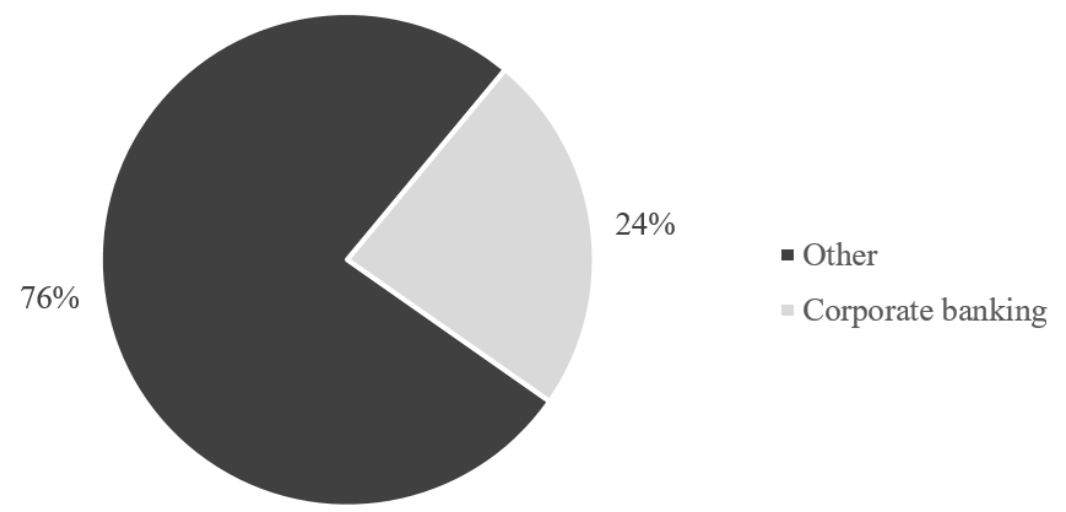

Fig. 3. Structure of credit portfolio by elements

Before proceeding to the economic capital allocation and estimation of $V a R$ contribution of the elements of the portfolio, $V a R$ was estimated on stand-alone base. The estimates of $V a R$ of the element and economic capital on stand-alone base displayed in Table 3 . The estimates of $V a R$ contribution and economic capital of elements applying Euler allocation presented in Table 4.

As it could be seen, in the case of estimation of economic capital on a standalone base, the sum of $E C$ of the elements is 19225 million Rub. which exceeds 
Table 3. Estimated values of $V a R, E L$, and $E C$ on stand-alone base by element

\begin{tabular}{llll}
\hline Element & $V a R_{0,95}$, mln.Rub & $E L$, mln.Rub & $E C$, mln.Rub \\
\hline Other & 18818 & 5718 & 13100 \\
Corporate & 12313 & 6188 & 6125 \\
Total & 31131 & 11907 & 19225 \\
\hline
\end{tabular}

the value of the portfolio-wide economic capital estimated on previous step, which amounted to 18279 million. This difference could be explained by the presence of the effect of diversification.

Table 4. Estimated values of $V a R, E L$, and $E C$ applying Euler allocation by element

\begin{tabular}{llll}
\hline Element & $C_{k}^{V a R_{0,95}}$, mln.Rub & $E L$, mln.Rub & EC, mln.Rub \\
\hline Other & 17142 & 5718 & 11423 \\
Corporate & 13043 & 6188 & 6855 \\
Total & 30185 & 11907 & 18279 \\
\hline
\end{tabular}

Commenting on the above results, it worth noting that as a result of applying the principle of Euler allocation, it was possible to allocate economic capital in such a way that the sum of the economic capital of the elements gives a total of portfolio economic capital and get the estimate of economic capital of corporate borrowers element. The main consumer of economic capital is element of other borrowers. This could be due to the fact that segment of other borrowers dominates in portfolio. The value of economic capital of corporate borrowers amounted to 6855 million Rub that is $37 \%$ of portfolio-wide economic capital.

\section{Conclusion}

The main goal of the study was to estimate economic capital to cover the credit risk of corporate borrowers of a commercial bank.

To achieve this goal, two main tasks were put forward, namely, the estimation of economic capital $(E C)$, in general, for the entire loan portfolio and its subsequent allocation to the elements of the credit portfolio and the assessment of the amount of economic capital to cover the credit risk of corporate borrowers.

The empirical study was conducted on actual data on credit portfolio of Russian commercial bank included in the top 20 of Russian banks by assets value. The economic capital was estimated on 01.01.2018.

In this paper, modelling of the distribution of losses carried out using the MonteCarlo simulation. The Vasicek model was used as a model for modelling losses of credit portfolio. This model is widely used by banks around the world and is recommended by the Basel Committee on Banking Supervision. Further, with the application of copulas, a joint distribution of losses over the credit portfolio was simulated. In the work the Gaussian copula was applied. Based on the resulting distribution of losses on the credit portfolio, portfolio VaR, expected losses were estimated and the total economic capital for credit risk coverage was calculated. 
The value of economic capital amounted to 18279 million Rub. The amount of expected losses amounted to 11907 million Rub.

At the next stage, using the Euler allocation method, economic capital was distributed among the elements of the portfolio. In order to apply this method the nonparametric method of kernel regression was used to estimate the conditional expectation, determined the contributions of individual elements of the credit portfolio to the total $V a R$ and to the portfolio-wide economic capital. As a result, the economic capital to cover the credit risk of corporate borrowers was estimated.

The following results were obtained. Firstly, the applying method of allocation allows to distribute total economic capital among elements in such a way that the sum of economic capital of elements equal to portfolio-wide economic capital.

Secondly, as a result of economic capital allocation to elements of corporate and other borrowers the economic capital of corporate borrowers was estimated. The value of economic capital of corporate borrowers amounted to 6855 million Rub that is $37 \%$ of portfolio-wide economic capital. In result of comparison of the estimate of economic capital for credit risk coverage of corporate borrowers with amount of realized unexpected losses was found that estimate turned out to quite conservative, on the one hand.

As a result of the work done, an estimation was made of the total economic capital to cover the credit risk of a commercial bank, as well as an estimate of economic capital to cover the credit risk of corporate borrowers. In order to achieve the results, the task of determining $V a R$ contribution and further economic capital contribution was solved applying Euler allocation method. In the study the kernel estimation was adapted in order to estimate conditional expectations required in the aforementioned method. Accurate economic capital allocation among elements of the portfolio and understanding of risk contributions of each element is very important for such purposes as optimization of portfolio, determination of concentration of risk of certain elements, estimation on risk-based performance measures and others. The results are helpful for the risk management of the commercial bank and supervisors.

\section{References}

Andersen, L. B. and J. Sidenius (2004). Extensions to the Gaussian copula: random recovery and random factor loadings. J Credit Risk, 1, 29-70.

An Explanatory Note on the Basel II IRB Risk Weight Functions / Basel Committee on Banking Supervision. - 2005. - available at: https://www.bis.org/bcbs/irbriskweight.pdf (accessed September 19, 2019)

Balog, D. (2011). Capital allocation in financial institutions: the Euler method. Discussion papers Institute of Economics, Hungarian Academy of Sciences.

Burns, R. L. (2004). Economic Capital and the Assessment of Capital Adequacy.- available at: https://www.fdic.gov/regulations/examinations/supervisory/insights/siwin04/ siwinter04-article1.pdf (accessed October 25,2019)

Credit risk modelling: current practices and applications / Basel Committee on Banking Supervision. - 1999. - available at: https://www.bis.org/publ/bcbs49.pdf (accessed September 19, 2019)

Choudhry, M. (2013). An Introduction to Value-at-Risk. 5th ed. John Wiley and Sons Ltd, The Atrium, Southern Gate, Chichester, West Sussex.

Fantazzini, D. (2008). Econometric analysis of financial data in risk management. In: SApplied econometrics Vol. 2(10), pp.91-137 (in Russian). 
Fenech, J.P., H. Vosgana and S. Shafik (2015). Loan default correlation using an Archimedean copula approach: A case for recalibration. Economic Modelling, 47(C), 340-354.

Finalising Basel III. In Brief / Basel Committee on Banking Supervision. - 2017. - available at: https://www.bis.org/bcbs/publ/d424inbrief.pdf (accessed September 19, 2019)

Fischer, M. and K. Jakob (2015). Copula-Specific Credit Portfolio Modeling. In: Innovations in Quantitative Risk Management (Glau, K., Scherer M., Zagst, R., eds), Springer, Cham.

Gourieroux, C., J.P. Laurent and O. Scaillet (2000). Sensitivity analysis of values at risk. Journal of Empirical Finance, 7, 225-245.

International Convergence of Capital Measurement and Capital Standards. A revised Framework Comprehensive version / Basel Committee on Banking Supervision. - 2006. - available at: https://www.bis.org/publ/bcbs128.pdf (accessed September 19, 2019)

Kalkbrener, M. (2005). An axiomatic approach to capital allocation. Mathematical Finance, 15(3), 425-437.

Klaasen, P. and I. Eeghen (2009). Economic capital: how it works and what every manager needs to know. Elsevier.

Lee, Y., S. Poon (2014). Forecasting and decomposition of portfolio credit risk using macroeconomic and frailty factors. Journal of Economic Dynamics and Control, 41, 69-92.

Lascells, D. and K. Patel (2015). Banking Banana Skins 2015: The CSFI survey of bank risk - available at:https://www.pwc.com/gx/en/financial-services/pdf/Bankingbanana-skins-2015-final.pdf

Lee, Y. and K. Yang (2019). Modelling diversification and spillovers of loan portfolios' losses by LHP approximation and copula. International Review of Financial Analysis, 66.

Litterman, R. (1996). Hot spots and hedges. The Journal of Portfolio Management, 22, $52-75$.

Lu, M., C. Chen and W.K. Hardle (2017). Copula-based factor model for credit risk analysis. Review of Quantitative Finance and Accounting, 49(4), 949-971.

Manuylenko, V. V. (2011). The concept of economic capital of a commercial Bank. Finance and credit, 13(445), 8-17.

Mausser, H. and D. Rosen (2007). Economic Credit Capital Allocation and Risk Contributions. In: Handbooks in Operations Research and Management Science, (Birge, J.R., Linetsky, V., eds.) Elsevier B.V.

Merton, R. (1974). On the pricing of corporate debt: the risk structure of interest rates. Journal of Finance, 2(29), 449-470.

Pagan, A. and A. Ullah (1999). Methods of Density Estimation. In: Nonparametric Econometrics. Cambridge: Cambridge University Press.

Range of practices and issues in economic capital frameworks/ Basel Committee on Banking Supervision. - 2009. - available at: https://www.bis.org/publ/bcbs152.pdf (accessed October 25, 2019)

Scandizzo, S. (2016). The Validation of Risk Models: A Handbook for Practitioners. 1st ed. Palgrave Macmillan, UK.

Shaw, R. A., A.D. Smith and G.S. Spivak (2011). Measurement and Modelling of Dependencies in Economic Capital. British Actuarial Journal, 16(3), 601-721.

Tasche, D. (1999). Risk contributions and performance measurement. Working paper Technische Universit $\Gamma$ at M $\mathrm{j}$ jnchen.

Tasche, D. (2006). Measuring sectoral diversification in an asymptotic multifactor framework. Journal of Credit Risk, 2(3), 33-55.

Tasche, D. (2008). Capital Allocation to Business Units and Sub-Portfolios: the Euler Principle. In: Pillar II in the New Basel Accord: The Challenge of Economic Capital. Risk Books.

Tasche, D. (2009). Capital Allocation for Credit Portfolios with Kernel Estimators. Quantitative Finance, 9(5), 581-595. 
Valaskova, K., A. Siekelova, and I. Weissova (2017). Credit Risk Measurement Using VaR Methodology. In: Advances in Applied Economic Research. (Tsounis, N., Vlachvei, A., eds.) Springer, Cham.

Vasicek, O. A. (2002). Loan portfolio value. Risk, 160-162.

Wang, M. (2016). Economic Capital Allocation. Mathematics and Statistics Faculty of Science and Engineering Abo Akademi University. 